\title{
Meteorological Response to a
}

Total Solar Eclipse

Adapted From

"The Total Solar

Eclipse of 2017," by

Rezaul Mahmood

(Kentucky Climate

(enter), Megan

Schargorodski, Eric

Rappin, Melissa

Griffin, Patrick

Collins, Kevin

Knupp, Andrew

Quilligan, Ryan

Wade, Kevin Cary, and Stuart Foster.

Published online

in BAMS, June

2020. For the full,

citable article, see

DOI:10.1175/BAMS

-D-19-0051.1.

\section{$\Delta$} * The total solar eclipse of 21 Aug 2017. Photo taken at Hopkinsville, Kentucky. (Photo courtesy of Joseph Matus.)

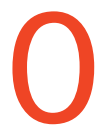

n 21 August 2017, a total solar eclipse traversed the continental United States, the first to do so in 99 years, providing a rare opportunity to observe the atmospheric response from a variety of platforms. It reached the point of greatest eclipse over western Kentucky, allowing the Kentucky Mesonet, operated by Western Kentucky University, to collect high-quality meteorological measurements with a high spatiotemporal density. This information was supplemented by a mesoscale network of three atmospheric profiling systems, operated by University of Alabama 
in Huntsville (UAH), along the path of totality near Hopkinsville, Kentucky.

The Bermuda high had settled into the southeastern United States. The skies were mostly clear with only widely scattered cumulus clouds, and the winds were weak along the path of totality across the state. Over Kentucky and the surrounding region, the air was generally relatively dry (dewpoint depression much greater than $5^{\circ} \mathrm{C}$ ). A stationary front was located over the upper Midwest and the northern Great Plains. With these ideal environmental conditions, the Kentucky Mesonet collected a wealth of data on the day of the eclipse.

We focused on the observed meso- and regional-scale response of the atmosphere, augmented by atmospheric modeling. It is the first time a mesoscale observation platform assessed solar radiation during a total eclipse in the United States.

\section{Networks}

The Kentucky Mesonet consists of 72 stations across the state that collect air temperature, precipitation, relative humidity, solar radiation, wind speed, and wind direction data. Each mesonet station site is representative of the area, including land cover and terrain, and meets scientific criteria for station and instrument exposure. For most variables, the network samples the atmosphere every $3 \mathrm{~s}$, calculates and records observations every 5 min, and subsequently distributes the data online. For this historic event, normal sampling frequency was adjusted to report data every $3 \mathrm{~s}$ for air temperature, incoming solar radiation, wind speed, and wind direction for all stations. This brought near-real-time data from stations within the path of totality but also from other stations, permitting a detailed investigation of the spatial and temporal variation. Additionally, to ensure the accuracy, key sensors were upgraded.

The UAH atmospheric profiling systems include wind profilers, thermodynamic profilers, lidar ceilometers, high temporal-resolution surface weather stations, and balloon soundings. The network collected thermodynamic and wind profiles every minute, as well as surface weather station data every $5 \mathrm{~s}$ for incoming solar radiation, air temperature, humidity, pressure, wind direction, and wind speed.

\section{Our study shows changes in solar radiation at the mesoscale under a total eclipse and fills a void between the micro- and continental scales that have been the focus of other studies.}

\section{Observations}

We provide data from the Kentucky Mesonet site at Warren County.

On a clear, stable day, like 21 August 2017, the expected smooth increase in solar radiation was observed after sunrise and throughout the morning (local time). Around 1700 UTC (1200 local time), as the partial solar eclipse arrived in this region, solar radiation started to decline from its peak of about $850 \mathrm{~W} \mathrm{~m}^{-2}$ to $0 \mathrm{~W} \mathrm{~m}^{-2}$ just prior to 1830 UTC (1330 local time; unsmoothed 3-s data) as totality settled in. As totality ended, the observed solar radiation also steadily increased until the partial eclipse ended around 2000 UTC ( 1500 local time) and subsequently declined following the diurnal cycle.

Our study shows changes in solar radiation at the mesoscale under a total eclipse and fills a void of observations and findings between the micro- and continental scales that have been the focus of other studies. Past eclipse studies in Europe all recorded a reduction of solar radiation and air temperature after the beginning, minimums during totality, and recovery as the eclipse ended. In addition, lowered wind speed, changes in wind direction, and increased relative humidity were also observed.

Internationally, meteorological observations and analyses were completed for a limited number of in situ sites, one of them in southwest Germany during a total solar eclipse on 11 August 1999 under mostly cloudy skies. This total eclipse occurred in the late morning ( $\sim 1130$ local time), and solar radiation declined to $0 \mathrm{~W} \mathrm{~m}^{-2}$, as in Kentucky. However, the decrease in solar radiation was not "smooth," as was observed in Kentucky, where clear skies prevailed. Hence, observations in Kentucky provided a better opportunity to verify our conceptual understanding of solar radiation changes during a total eclipse.

Regional changes in air temperature can also be seen from the Kentucky Mesonet: $30^{\circ}-34^{\circ} \mathrm{C}$ during the beginning (1705 UTC) of the eclipse, decreasing to $20^{\circ}-29^{\circ} \mathrm{C}$ near totality (1825 UTC), and then rebounding to $30^{\circ}-34^{\circ} \mathrm{C}$ post-eclipse (1945 UTC).

Due to stable conditions from the Bermuda high and absence of widespread large-scale moist flow from the Gulf of Mexico, relative humidity changes were largely linked to temperature changes. In Warren County, air temperature increased and relative humidity 
a)

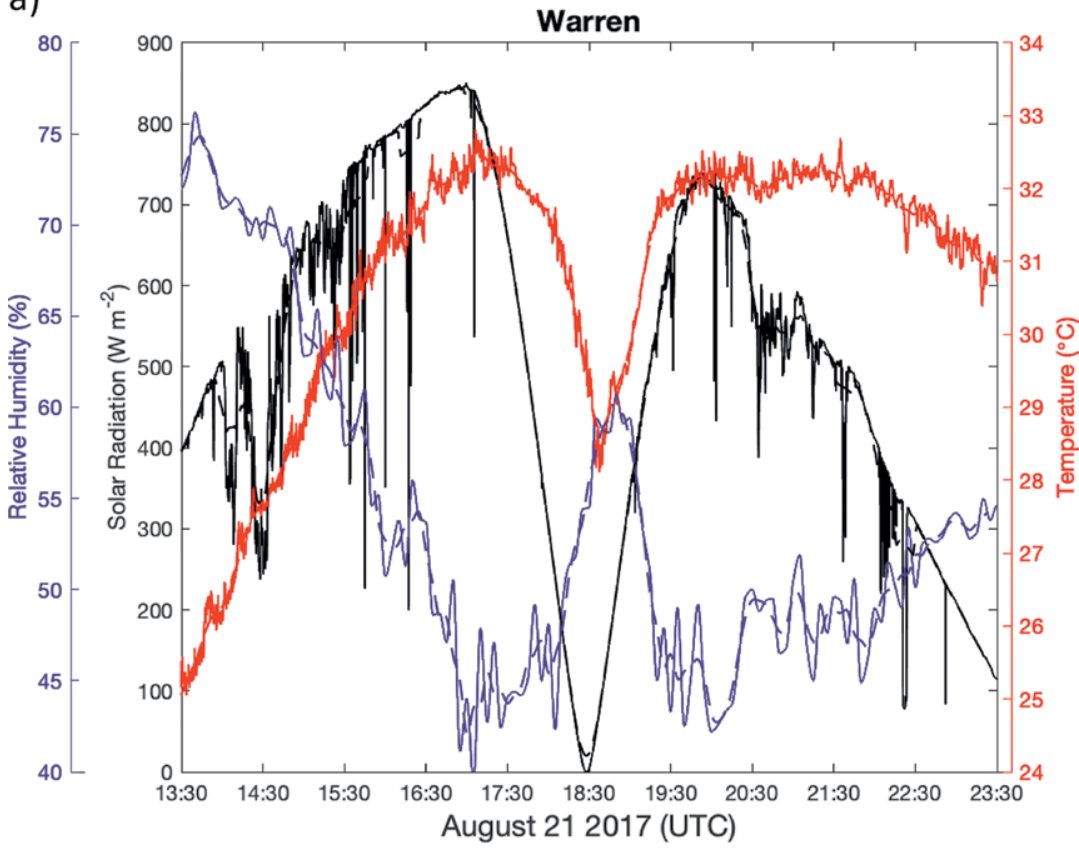

b)

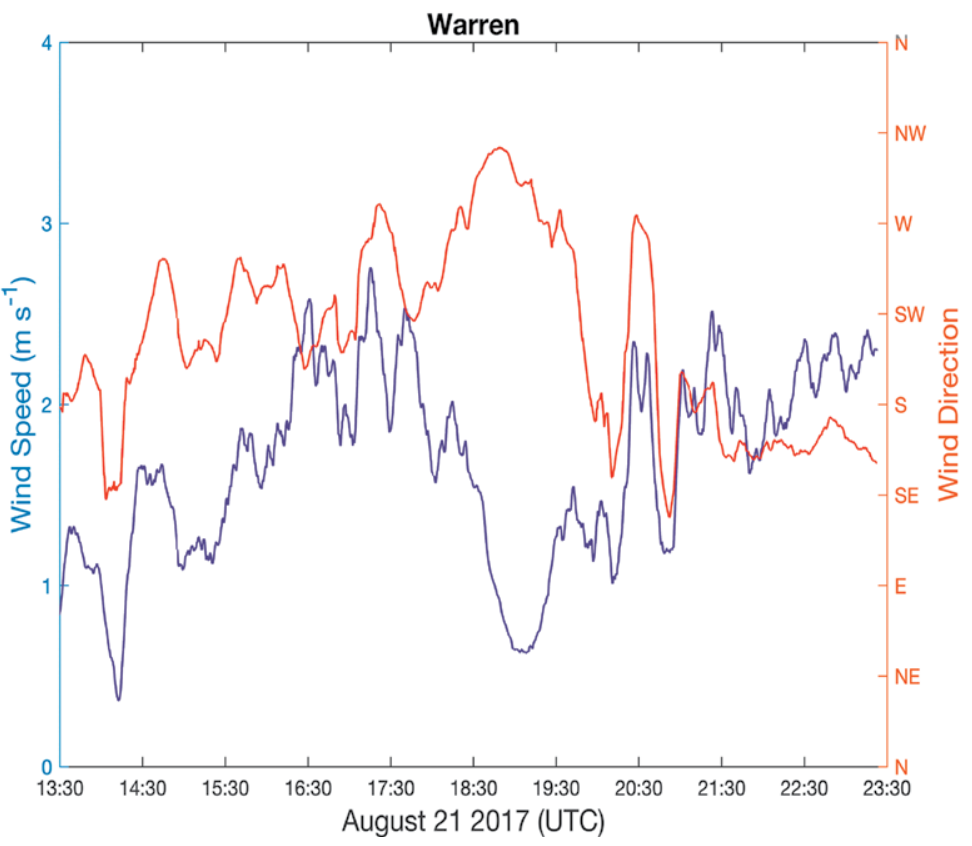

decreased from roughly $75 \%$ to near $40 \%$ in the morning prior to the beginning of the eclipse. On the other hand, during totality, relative humidity rapidly increased to about $60 \%$. After the end of the eclipse, relative humidity again decreased to about $42 \%$.

Due to high pressure over the region, the weak wind primarily reflected thermal forcing from daytime solar heating. With the loss of daytime heating during the eclipse, the thermal circulation began to collapse as the boundary layer began to stabilize. Wind speed steadily declined once the eclipse commenced, reaching a minimum during totality. At Todd County, wind speed declined from its maximum of about 2.5 to $0 \mathrm{~m} \mathrm{~s}^{-1}$ during the total eclipse.

Surface wind backed at all three locations, and as totality ended, the wind direction veered (clockwise) back to near its original direction. Regionally, the response of surface wind was similar-that is, generally backing during the totality and veering toward the pre-eclipse direction after the end of the totality. This was also consistent with previous observations under total and partial solar eclipses in the other parts of the world.

Data from mesonet stations in Todd, Christian, and Trigg Counties were generally consistent with data from the Warren County station. These three zonally oriented stations were within the path of totality. Solar radiation decreased from more than 800 to $0 \mathrm{~W} \mathrm{~m}^{-2}$ from prior to the eclipse to totality at each station. Air temperatures also declined, at some sites more than $4^{\circ} \mathrm{C}$. The peak decline at each location was up to 15 min after totality, as buoyant turbulence takes time to dissipate as the boundary layer stabilizes. With little Gulf moisture, relative humidity followed the air temperature evolution and declined through the morning before the solar eclipse. All three stations showed a rapid rise from about $45 \%$ to about $75 \%$ during totality. Following the eclipse, relative humidity quickly lowered to near 50\% or lower. As solar radiation returned, air temperature also increased and relative humidity declined to nearpre-eclipse levels.

\section{Boundary layer response}

The characteristic growth of the PBL occurred under mostly clear skies and is clearly evident in profiler data. The most prominent eclipse signal is the rapid reduction in turbulent 


\begin{tabular}{|c|c|c|c|c|c|c|c|c|}
\hline $\begin{array}{l}\text { Location } \\
\text { (by county) }\end{array}$ & Time (UTC) & LE $\left(W^{-2}\right)$ & $H\left(W^{-2}\right)$ & RH (\%) & $T_{\text {air }}\left({ }^{\circ} \mathrm{C}\right)$ & $\begin{array}{l}\text { WSPD } \\
(\mathrm{m} \mathrm{s}-1)\end{array}$ & WDIR $\left(^{\circ}\right)$ & PBLH (m) \\
\hline \multirow[t]{4}{*}{ Warren } & 1705 & 357 (375) & 161 (178) & $51(51)$ & $31.8(31.9)$ & $2.9(2.9)$ & 191 (191) & $1,336(1,336)$ \\
\hline & 1825 & 7 (384) & $-12(176)$ & $57(47)$ & $29.0(32.5)$ & $2.2(2.1)$ & 179 (190) & $43(930)$ \\
\hline & 1945 & 317 (358) & 117 (146) & $50(48)$ & $31.7(32.7)$ & $3.8(3.6)$ & 177 (182) & $1,337(1,120)$ \\
\hline & Mean & $174(380)$ & 44 (172) & $55(48)$ & $30.6(32.5)$ & $2.7(2.8)$ & $185(190)$ & $502(1,252)$ \\
\hline \multirow[t]{4}{*}{ Christian } & 1705 & $413(447)$ & 111 (133) & $51(51)$ & $31.1(31.2)$ & $3.0(3.0)$ & 207 (207) & $766(766)$ \\
\hline & 1825 & $0(471)$ & $-15(118)$ & $53(44)$ & $28.0(32.1)$ & $1.7(1.9)$ & $233(236)$ & $43(1,591)$ \\
\hline & 1945 & $380(434)$ & 86 (91) & $50(44)$ & $30.9(32.4)$ & $2.9(2.6)$ & 199 (196) & $766(1,337)$ \\
\hline & Mean & 199 (461) & 24 (116) & $54(46)$ & $29.8(32.0)$ & $2.2(2.5)$ & $220(222)$ & $439(1,306)$ \\
\hline \multirow[t]{4}{*}{ Todd } & 1705 & $377(404)$ & 137 (157) & $52(50)$ & $31.7(31.8)$ & $2.7(2.7)$ & 207 (207) & $1,335(1,335)$ \\
\hline & 1825 & $3(418)$ & $-11(155)$ & $55(47)$ & $29.0(32.5)$ & $1.4(2.0)$ & 205 (214) & $43(1,899)$ \\
\hline & 1945 & 341 (386) & 107 (126) & $50(48)$ & $31.5(32.9)$ & $3.0(2.9)$ & 197 (176) & $1,336(1,904)$ \\
\hline & Mean & $183(409)$ & 36 (151) & $54(48)$ & $30.5(32.4)$ & $2.1(2.2)$ & $198(204)$ & $820(1,791)$ \\
\hline \multirow[t]{4}{*}{ Lewis } & 1705 & 424 (424) & 179 (179) & $54(54)$ & $31.0(31.0)$ & $3.7(3.7)$ & $237(237)$ & $1,111(1,111)$ \\
\hline & 1825 & 44 (431) & $-17(168)$ & $64(50)$ & $28.4(31.7)$ & $2.4(3.8)$ & $236(236)$ & $43(1,591)$ \\
\hline & 1945 & 334 (93) & $104(-19)$ & $56(58)$ & $30.7(29.9)$ & $3.1(2.5)$ & $200(211)$ & $765(1,896)$ \\
\hline & Mean & $214(400)$ & $44(151)$ & $60(52)$ & $29.7(31.5)$ & $2.8(3.5)$ & $225(231)$ & $667(1,452)$ \\
\hline
\end{tabular}

motions within the PBL, as indicated by lidar. The PBL collapsed top down, with significant Doppler Wind Lidar (DWL) vertical motions and $915-\mathrm{Hz}$ turbulence both decreasing to low values prior to totality. Unusually rapid growth of the PBL resumed near 1940 UTC, about $25 \mathrm{~min}$ after the 50\% totality mark. DWL $w$ patterns reveal regular wave motions, which appear to be most significant near the capping inversion (as expected) around the time of totality.

The radiometer showed cooling was confined below about $100 \mathrm{~m} \mathrm{AGL}$, with a corresponding increase in water vapor consistent with the expected reduction in turbulent water vapor flux and evapotranspiration confined to a shallow, stable surface layer. The Microwave Profiling Radiometer (MPR) air temperature field reveals an unexpected warm column within the 500-600-m AGL layer above the low-level cool pool. This warming is consistent with subsidence measured directly by the DWL around the time of totality, yet it would not be expected within descending air if the residual layer had a constant potential temperature with height. Posteclipse soundings confirmed the surface and PBL recovery with the 2100 UTC sounding exhibiting a well-mixed, nearly dry adiabatic
* Modeled parameters without solar forcing (with solar forcing in parentheses) at 1705, 1825, and 1945 UTC and the 1705-1945 UTC mean. Without solar forcing assumes a solar eclipse. Totality occurred near 1825 UTC. Abbreviations are as follows: $L E=$ latent heat flux, $\mathrm{H}=$ sensible heat flux, RH = relative humidity, Tair = air temperature, WS = wind speed, WDIR = wind direction, and PBLH $=$ planetary boundary layer height.
PBL down to the surface, and the 2230 UTC sounding indicating a superadiabatic surface layer, although not as deep as the 1700 UTC pre-eclipse sounding.

\section{Analysis using model}

With a version of the Weather Research and Forecasting (WRF) Model specifically adapted for the study of the evolution of the atmosphere during solar eclipses, we ran a 30 -h simulation from 0000 UTC 21 August to 0600 UTC 22 August 2017 with and without the eclipse (i.e., without and with solar forcing). While analysis of the Mesonet and profiler network was based on the observed difference between values of meteorological parameters before, during, and after the eclipse, the WRF model assessment was based on the simulated difference in values between these parameters with and (hypothetically) without the eclipse.

The model satisfactorily captures the Mesonet-observed changes in solar radiation, air temperature, and sensible and latent heat flux as the eclipse slowly reaches totality and eventually concludes. The simulations are in phase with the observations. In particular, the best agreement is observed from the beginning to the end of the solar eclipse. During totality, simulated solar radiation, 
like observations, reached $0 \mathrm{~W} \mathrm{~m}^{-2}$ and air temperature dropped to $28.7^{\circ} \mathrm{C}$. These agreements provide further confidence in our model-based assessment.

Further assessment of the regional meteorology, including over neighboring Missouri and Arkansas, was based on the WRF simulations. There was broad consistency between mesoscale and regional response as well as between simulated and observed response to the reduction or absence of solar radiation due to the eclipse.

At the time the solar eclipse commences over Missouri and Arkansas, solar radiation is $\sim 600 \mathrm{~W} \mathrm{~m}^{-2}$ greater in the no-eclipse simulation. During totality, this difference is up to $\sim 1000 \mathrm{~W} \mathrm{~m}^{-2}$ over Kentucky. As the eclipse ends across the region, the simulation differences decrease to less than 100-200 W m $\mathrm{m}^{-2}$. Air temperature and sensible and latent heat fluxes follow the same pattern. For example, air temperatures are up to $2{ }^{\circ} \mathrm{C}$ higher in Missouri and Arkansas at 1740 UTC in the no-eclipse simulation, and up to 6 ${ }^{\circ} \mathrm{C}$ higher in western Kentucky and surrounding regions at 1825 UTC of the no-eclipse simulation. Those differences diminish to less than $2^{\circ} \mathrm{C}$ at 1940 UTC when the solar eclipse is ending.

Modeled PBL heights also show, as expected, lowering or collapse during totality. For example, in Todd County, the PBL is reduced to $43 \mathrm{~m}$ as boundary layer convective mixing ceases, while it is $1,335 \mathrm{~m}$ at the beginning of the eclipse. After the eclipse, prior to full boundary layer recovery, the dew point depression grows. Given the synoptic setting, it is unsurprising that the simulated boundary layer does not saturate except in the Todd County location near the base of the capping inversion. The biggest declines in air temperature are at the surface with larger boundary layer changes beneath the inversion after totality.

Sensible and latent heat fluxes follow the same pattern. In Todd County, simulated latent heat fluxes decrease from 377 to $3 \mathrm{~W} \mathrm{~m}^{-2}$ and sensible heat flux from 137 to $-11 \mathrm{~W} \mathrm{~m}^{-2}$ in the no-eclipse and with-eclipse simulations, respectively. During totality, the simulated air temperature decreases $2.5^{\circ}-4^{\circ} \mathrm{C}$, broadly consistent with Kentucky Mesonet observations. Simulated wind speeds also show up to a $1.3-\mathrm{m} \mathrm{s}^{-1}$ reduction from the beginning of the solar eclipse $\left(3.0 \mathrm{~m} \mathrm{~s}^{-1}\right)$ to the period

\section{$\equiv$ METADATA}

BAMS: What would you like readers to learn from this article?

Rezaul Mahmood: Observations collected during the total eclipse clearly show that the absence of sunlight-even for a couple of minutes-notably impacts weather conditions.

BAMS: The eclipse itself was certain, but not the weather...

RM: We were fortunate to experience a clear-sky condition during the total solar eclipse. As a result, we were able to observe and further verify what we knew about the behavior of the near-surface and lower atmosphere in response to the solar radiation and its absence.

BAMS: What was the biggest challenge you encountered while doing this work?

RM: It was many hours of planning and additional work over a number of months for our staff to prepare the network and atmospheric profiling system for the total eclipse. We had one shot at it with the hope that the weather would cooperate. And it did.

BAMS: How would you like to follow up on this project?

RM: During future eclipses, it would be more interesting to collect more data (and conduct analysis) from other parts of the world.

of totality $\left(1.7 \mathrm{~m} \mathrm{~s}^{-1}\right)$ over Christian County in Kentucky.

\section{Summary}

This was an unprecedented opportunity to document atmospheric response to a historic solar eclipse at the meso- and regional scales. Observations and modeling supported our conceptual understanding of potential atmospheric response due to the absence of solar radiation during the height of a summer season day. Finally, this research is complementary to localor continental-scale studies on the same topic and offered additional insight on the atmospheric response to total solar eclipse for these scales. $\bullet$. 


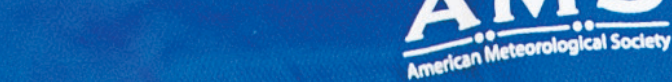

\section{AMS AMS}
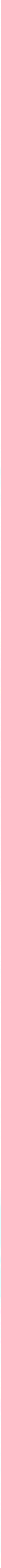